\title{
BMJ Open Birth cohort trends in the global epidemiology of alcohol use and alcohol-related harms in men and women: systematic review and metaregression
}

\author{
Tim Slade, ${ }^{1}$ Cath Chapman, ${ }^{1}$ Wendy Swift, ${ }^{1}$ Katherine Keyes, ${ }^{2}$ Zoe Tonks, ${ }^{1}$ \\ Maree Teesson ${ }^{1}$
}

To cite: Slade T, Chapman C, Swift W, et al. Birth cohort trends in the global epidemiology of alcohol use and alcohol-related harms in men and women: systematic review and metaregression. BMJ Open 2016;6:e011827. doi:10.1136/bmjopen-2016011827

- Prepublication history and additional material is available. To view please visit the journal (http://dx.doi.org/ 10.1136/bmjopen-2016011827).

Received 8 March 2016 Revised 10 June 2016 Accepted 1 August 2016

\section{CrossMark}

${ }^{1}$ NHMRC Centre of Research Excellence in Mental Health and Substance Use, National Drug and Alcohol Research Centre, University of New South Wales, Randwick, New South Wales, Australia ${ }^{2}$ Columbia University, Mailman School of Public Health, New York, New York, USA

Correspondence to Dr Tim Slade;

tims@unsw.edu.au

\section{ABSTRACT}

Objective: Historically, alcohol use and related harms are more prevalent in men than in women. However, emerging evidence suggests the epidemiology of alcohol use is changing in younger cohorts. The current study aimed to systematically summarise published literature on birth cohort changes in male-tofemale ratios in indicators of alcohol use and related harms.

Methods: We identified 68 studies that met inclusion criteria. We calculated male-to-female ratios for 3 broad categories of alcohol use and harms (any alcohol use, problematic alcohol use and alcoholrelated harms) stratified by 5 -year birth cohorts ranging from 1891 to 2001, generating 1568 sex ratios. Random-effects meta-analyses produced pooled sex ratios within these 3 categories separately for each birth cohort.

Findings: There was a linear decrease over time in the sex ratio for all 3 categories of alcohol use and related harms. Among those born in the early 1900s, males were $2.2(95 \% \mathrm{Cl} 1.9$ to 2.5$)$ times more likely than females to consume alcohol, $3.0(95 \% \mathrm{Cl} 1.5$ to 6.0$)$ times more likely to drink alcohol in ways suggestive of problematic use and $3.6(95 \% \mathrm{Cl} 0.4$ to 30.3$)$ times more likely to experience alcohol-related harms. Among cohorts born in the late 1900s, males were 1.1 $(95 \% \mathrm{Cl} 1.1$ to 1.2$)$ times more likely than females to consume alcohol, $1.2(95 \% \mathrm{Cl} 1.1$ to 1.4$)$ times more likely to drink alcohol in ways suggestive of problematic use and $1.3(95 \% \mathrm{Cl} 1.2$ to 1.3$)$ times more likely to experience alcohol-related harms.

Conclusions: Findings confirm the closing malefemale gap in indicators of alcohol use and related harms. The closing male-female gap is most evident among young adults, highlighting the importance of prospectively tracking young male and female cohorts as they age into their 30s, 40s and beyond.

Alcohol use and alcohol-related harms are among the most significant risk factors for burden of disease. Overall, they resulted in

\section{Strengths and limitations of this study}

- Prior to this study, the evidence around gender convergence in alcohol use and alcohol-related harms was fragmented. This study systematically summarised all available literature and provided a quantification of the rate of gender convergence through the derivation of a single metric -the male-to-female ratio in alcohol use and alcohol-related harms.

- This study was strengthened by its examination of 11 separate indicators of alcohol use and alcohol-related harms, summarised in three broad categories and showed that gender convergence was evident across all indicator categories.

- While the derivation of a single metric facilitated numerical synthesis of data, the analyses are not independent of measurement variance.

- The current study did not test specific hypotheses for why the male-female gap in alcohol use and alcohol-related harms is closing.

around 5 million deaths globally in 2010, and were responsible for more than 161 million years of life lost, equating to $5 \%$ of total global health burden. ${ }^{1}$ Historically, the prevalence of alcohol use and related harms has been between 2 and 12 times higher in men than women. ${ }^{2-7}$ However, there is emerging evidence to suggest that the gap between men and women in alcohol use and related harms is closing among recently born cohorts. $^{8-11}$ Understanding sex-specific birth cohort trends in the epidemiology of alcohol use is vital as they point to key environmental and social mechanisms associated with population shifts in alcohol use patterns. For example, studies have attributed these generational shifts in sex-specific drinking to changes in traditional gender roles over 
time ${ }^{5}$ changes in sex-specific attitudes towards drinking $^{12}$ and/or changes in the contexts and environments in which men and women now drink. ${ }^{4}$ Furthermore, substantial changes over time in the sex distribution of alcohol use may require a rethink of effective health policies, resource allocation models and intervention strategies to combat the societal costs associated with use. In fact, a recent evidence synthesis of the effectiveness of population-level alcohol policy interventions argued that with shifting sex-specific population trends in alcohol use, there is a pressing need to understand the effectiveness of policy interventions separately for males and females. ${ }^{13}$

Several individual studies have empirically addressed the question of sex differences in birth cohort effects on alcohol use. The most methodologically rigorous of these employs age-period-cohort (APC) modelling, a statistical approach designed to isolate temporal changes in prevalence that are independently associated with being in a specific birth cohort from changes associated with a specific age and/or a particular historical period. A subset of these APC analyses has examined whether the birth cohort effect is of the same magnitude for men and women and reported mixed evidence. ${ }^{14-18}$ For example, analysing data from the Finnish Drinking Habits Survey, Harkonen and Makela ${ }^{14}$ found male-to-female convergence in the frequency of heavy episodic drinking (defined as 6+ drinks on one occasion for males and 4+ drinks on one occasion for females) in recent cohorts. However, Keyes and Miech ${ }^{17}$ demonstrated that while heavy episodic drinking (defined as $5+$ drinks on one occasion for males and females) decreased in recent birth cohorts, there was little evidence of sex differences in this cohort effect. Over and above these APC studies, a wider body of literature has explored, in more indirect ways, the changing epidemiology of alcohol use over time. A narrative synthesis carried out nearly 10 years ago concluded that the male-female gap in alcohol problems appears to be narrowing in some countries. ${ }^{19}$

However, in this narrative synthesis, sex convergence was not numerically quantified making it difficult to judge the extent of the convergence. Moreover, the published literature on sex convergence in alcohol use has nearly doubled in size since 2008 indicating a timely need to revisit this issue. We report the results of a systematic review and meta-analysis of the male-to-female ratio in key indicators of alcohol use and related harm to enumerate the magnitude of any observed malefemale convergence in alcohol use and related harms over time.

\section{METHODS}

The current systematic review followed guidelines for the conducting and reporting of Meta-analyses Of Observational Studies in Epidemiology $\left(\mathrm{MOOSE}^{20}\right.$ ) and the Preferred Reporting Items for Systematic Reviews and Meta-Analyses (PRISMA). ${ }^{21} 22$ The final reporting was informed by the findings of a systematic review of meta-analyses of observational studies in psychiatric epidemiology. ${ }^{23}$ We used EppiReviewer V.4 for the management of screening, coding and data extraction (EPPI-Reviewer 4.0: software for research synthesis. EPPI-Centre Software [program]. London: Social Science Research Unit, Institute of Education, University of London, 2010).

\section{Study inclusion criteria}

We used search terms that aimed to identify studies that reported on the following indicators of alcohol use and related harm: lifetime and/or current alcohol use disorder (abuse or dependence); alcohol-related problems (eg, drunkenness, other negative consequences), alcohol-related treatment seeking; stages in the alcohol use and related problems cycle (eg, onset of use, transition from use to disorder). We also explicitly looked for studies reporting data on commonly investigated drinking patterns (eg, heavy episodic or binge drinking). We included studies published between January 1980 and June 2014 inclusive that:

1. Measured at least one of the above indicators of alcohol use or related harm;

2. Reported on a regionally or nationally representative population sample;

3. Explicitly measured a cohort effect or presented indicator data across at least two birth cohorts; and

4. Presented indicator data separately for males and females or carried out explicit comparisons between males and females (this included sex by time or sex by cohort interactions).

We included studies based on samples of high school or college students where these samples were regionally or nationally representative. We excluded studies that only sampled targeted groups within the population (eg, people seeking treatment). The decision was made to focus only on representative population samples in order to characterise overall changes in general population means and prevalence estimates at regional and national levels. Full electronic search strategies including search terms are contained in tables 1-3.

\section{Search strategy}

We searched three databases (MEDLINE, EMBASE, PsychINFO) using three separate search strategies. The search strategies were developed by TS and CG in consultation with the librarian at the National Drug and Alcohol Research Centre (MK).

Search strategy 1 aimed to identify studies that explicitly derived parameter estimates of changes over time in indicators of alcohol use and related harms. This strategy focused on keywords that are commonly used to describe APC analyses and these were combined with database-specific MeSH headings and keywords for alcohol use and related harms. Relevant MeSH terms were identified separately in each database and were 
Table 1 Full electronic search strings for search strategy 1: studies that explicitly derived parameter estimates that reflect changes over time in indicators of alcohol and cannabis use and related harms

\begin{tabular}{|c|c|c|}
\hline Database & $\begin{array}{l}\text { Search } \\
\text { group }\end{array}$ & Search terms \\
\hline \multirow[t]{2}{*}{ EMBASE } & Alcohol & $\begin{array}{l}\mathrm{SH} \text { : exp alcohol consumption/ OR exp alcoholism/ OR exp alcohol abuse/ OR exp } \\
\text { drinking behavior/ OR exp alcohol intoxication/ }\end{array}$ \\
\hline & Cannabis* & $\begin{array}{l}\mathrm{SH} \text { : exp cannabis/ OR exp substance abuse/ OR exp drug abuse/ OR exp drug } \\
\text { dependence/ OR marijuana.mp (marijuana used as a keyword because not } \\
\text { mapped to separate MeSH) }\end{array}$ \\
\hline \multirow[t]{2}{*}{ PsychINFO } & Alcohol & SH: exp Alcohol Drinking Patterns/ \\
\hline & Cannabis* & SH: exp cannabis/ OR exp marijuana usage/ OR exp Drug abuse/ \\
\hline MEDLINE & Alcohol & SH: exp alcohol drinking/ OR exp alcohol-related disorders/ \\
\hline & Cannabis* $^{*}$ & SH: exp cannabis/ OR exp marijuana abuse/ OR exp substance-related disorders/ \\
\hline EMBASE, PsychINFO, & Cohort & ((age period and cohort) OR cohort effect OR secular trend OR secular change OR \\
\hline MEDLINE & Effect & $\begin{array}{l}\text { time trend OR cohort trend OR birth cohorts OR younger cohort OR older cohort } \\
\text { OR recent cohort OR earlier cohort).mp }\end{array}$ \\
\hline
\end{tabular}

'exploded' to capture the broadest possible set of alcohol studies. When subject headings did not accurately cover the target domain, we added .mp to the search term (see table 1).

Search strategy 2 aimed to identify studies that focused on sex differences in alcohol use and related harms but did not explicitly conduct APC analyses. This strategy included search terms related to sex or gender, sex or gender convergence and sex or gender gap, and these were combined with the broad database-specific terms for alcohol and related harm outlined for search strategy 1 (see table 2).

Search strategy 3 aimed to identify studies that reported data split by sex and birth cohorts or by sex and age groups (as a proxy for birth cohorts) but did not explicitly conduct APC analysis or examine sex convergence. In order to obtain adequate sensitivity and specificity, this search was restricted to gold standard epidemiological studies based on guidelines developed for the WHO 2010 Global Burden of Disease study protocols ${ }^{24}$ and used narrower terms to capture studies that have focused on alcohol use and related harms.

The initial search of the three databases was undertaken in January 2013 and then updated at the end of June 2014. All article abstracts were screened independently by one of the authors (TS, CG or ZT) to exclude those that were ineligible for inclusion. We obtained full texts of remaining articles, and the same authors independently assessed them in detail for inclusion. Non-English texts were not included in the review. Approximately $20 \%$ of abstracts and full-text articles were independently screened by a second reviewer. The electronic search strategy was supplemented by hand-searching of existing literature reviews and

Table 2 Full electronic search strings for search strategy 2: studies that focused on gender differences in alcohol or cannabis use and related harms but did not explicitly conduct age-period-cohort analyses

\begin{tabular}{|c|c|c|}
\hline Database & $\begin{array}{l}\text { Search } \\
\text { group }\end{array}$ & Search terms \\
\hline \multirow[t]{2}{*}{ EMBASE } & Alcohol & $\begin{array}{l}\text { SH: exp alcohol consumption/ OR exp alcoholism/ OR exp alcohol abuse/ OR exp } \\
\text { drinking behavior/ OR exp alcohol intoxication/ }\end{array}$ \\
\hline & Cannabis* & $\begin{array}{l}\mathrm{SH} \text { : exp cannabis/ OR exp substance abuse/ OR exp drug abuse/ OR exp drug } \\
\text { dependence/OR marijuana.mp (marijuana used as a keyword because not mapped } \\
\text { to separate } \mathrm{MeSH} \text { ) }\end{array}$ \\
\hline \multirow[t]{2}{*}{ PsychINFO } & Alcohol & SH: exp Alcohol Drinking Patterns/ \\
\hline & Cannabis* & SH: exp cannabis/ OR exp marijuana usage/ OR exp Drug abuse/ \\
\hline \multirow[t]{2}{*}{ MEDLINE } & Alcohol & SH: exp alcohol drinking/ OR exp alcohol-related disorders/ \\
\hline & Cannabis* & SH: exp cannabis/ OR exp marijuana abuse/ OR exp substance-related disorders/ \\
\hline $\begin{array}{l}\text { EMBASE, PsychINFO, } \\
\text { MEDLINE }\end{array}$ & Gender & $\begin{array}{l}\text { (((male AND female) OR (men AND women) OR sex OR gender) AND } \\
\text { convergence).mp OR 'gender gap'.mp }\end{array}$ \\
\hline
\end{tabular}


Table 3 Full electronic search strings for search strategy 3: studies which have examined indicators of alcohol or cannabis use or related harms by gender and birth cohort or gender and age groups (as a proxy for birth cohorts) but did not explicitly conduct age-period-cohort analysis or focus on gender convergence

\begin{tabular}{|c|c|c|}
\hline Database & Search group & Search terms \\
\hline \multirow[t]{4}{*}{ EMBASE } & Alcohol & $\begin{array}{l}\text { SH: exp *alcohol consumption/ OR exp *alcoholism/ OR exp *alcohol } \\
\text { abuse/ OR exp *drinking behavior/ OR exp *alcohol intoxication/ }\end{array}$ \\
\hline & Cannabist & $\begin{array}{l}\mathrm{SH} \text { : exp *cannabis/ OR *substance abuse/ OR *drug abuse/ OR *drug } \\
\text { dependence/ OR *drug abuse pattern/ OR *cannabis addiction/ }\end{array}$ \\
\hline & $\begin{array}{l}\text { Gold Standard } \\
\text { Epidemiology }\end{array}$ & $\begin{array}{l}\mathrm{SH}: \exp { }^{*} \text { population/OR exp *health survey/OR exp *health care survey/ OR } \\
\text { (general population OR general community OR survey OR representative). } \\
\mathrm{mp}\end{array}$ \\
\hline & Indicator & $\begin{array}{l}\text { SH: exp *prevalence/OR exp *help seeking behaviour/OR exp *health care } \\
\text { utilization/ OR (prevalence OR health care utilization OR health care } \\
\text { utilisation OR help seeking behaviour OR help seeking behaviour OR } \\
\text { treatment seeking or service utilisation or service utilization).mp }\end{array}$ \\
\hline \multirow[t]{5}{*}{ PsychINFO } & Alcohol & SH: exp *Alcohol Drinking Patterns/ \\
\hline & Cannabist & $\begin{array}{l}\text { SH: exp *cannabis/ OR exp *marijuana usage/ OR *drug abuse/ OR *drug } \\
\text { dependency/ }\end{array}$ \\
\hline & Gold Standard & SH: exp *surveys/ OR (general population OR general community OR \\
\hline & Epidemiology & survey OR representative).mp \\
\hline & Indicator & $\begin{array}{l}\text { SH: exp *help seeking behavior/OR exp *health care utilization/ OR } \\
\text { (prevalence OR health care utilization OR health care utilisation OR help } \\
\text { seeking behaviour OR help seeking behaviour OR treatment seeking).mp }\end{array}$ \\
\hline \multirow[t]{4}{*}{ MEDLINE } & Alcohol & SH: exp *alcohol drinking/ OR exp *alcohol-related disorders/ \\
\hline & Cannabist & $\begin{array}{l}\text { SH: exp *cannabis/ OR exp *marijuana abuse/ OR exp *substance-related } \\
\text { disorders }\end{array}$ \\
\hline & $\begin{array}{l}\text { Gold Standard } \\
\text { Epidemiology }\end{array}$ & $\begin{array}{l}\text { SH: exp *health surveys/ OR exp *health care surveys/ OR (general } \\
\text { population OR general community OR survey OR representative).mp }\end{array}$ \\
\hline & Indicator & $\begin{array}{l}\mathrm{SH} \text { : exp *prevalence/ OR (prevalence OR health care utilization OR health } \\
\text { care utilisation OR help seeking behaviour OR help seeking behaviour OR } \\
\text { treatment seeking).mp }\end{array}$ \\
\hline $\begin{array}{l}\text { EMBASE, PsychINFO, } \\
\text { MEDLINE }\end{array}$ & Age & (younger or older).mp \\
\hline
\end{tabular}

reference lists of key papers. TS developed the screening and data extraction codes in EppiReviewer, and CC and ZT extracted data from included studies. WS and KK advised on the qualitative synthesis, and WS checked extracted data from all included studies. TS checked extracted data for all studies included in the meta-analysis.

Figure 1 shows the number of articles obtained using the search strategy and number of records excluded with reasons. The present study had a secondary aim of examining evidence for the closing sex gap in indicators of cannabis use, and the screening protocol was designed to screen records for alcohol and cannabis. Findings with respect to cannabis are presented in another paper (Chapman et al, under review). The electronic search strategy identified 1445 unique records and an additional 20 records were retrieved via examining existing literature reviews and reference lists of key papers. After screening abstracts, 314 full-text articles were retrieved and examined for inclusion. A total of 68 papers met the alcohol-related inclusion criteria. Quantitative synthesis was conducted on 50 studies. (online supplementary file) provides detailed characteristics of all included studies by individual citation. Table 4 provides summary characteristics of all included studies.

\section{Data extraction}

Data were extracted in the following domains: study design, population, country, survey name, survey year, sample age, sample size, birth cohorts covered, indicators reported including indicator definitions, definition timeframe and whether the authors reported evidence of gender convergence on any indicators of interest. Studies varied in the parameters used to define alcohol use and related harms. For example, studies reporting data on prevalence of any alcohol use differed with regard to timeframe (lifetime, past 12 months, current), definition of alcohol use (one or more standard drinks, $12+$ or more standard drinks), frequency of drinking (weekly, monthly, yearly) and whether a continuous or categorical measure was used. Similarly, studies that measured alcohol-related harms (eg, abuse and dependence, alcohol-related problems) differed in terms of diagnostic 
3905 records identified through database searching (Medline, PsychInfo, Embase)
20 additional records identified through other sources (eg reference lists of key papers)

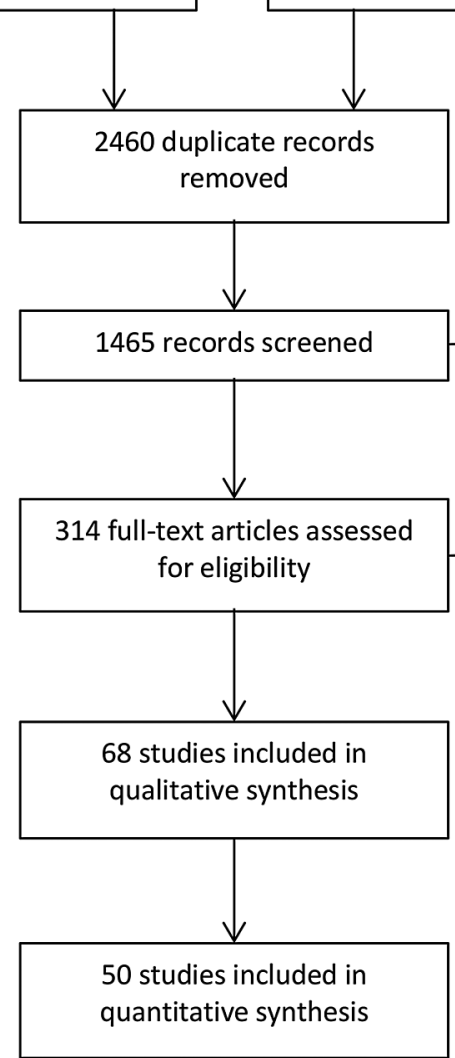

1151 records excluded

- Not reported indicator by gender $n=73$

- Not reported indicator of interest $n=36$

- Non-representative sample $n=25$

- Data extracted from another citation $n=1$

- Study reported data on cannabis only $(n=15)^{*}$

* Cannabis indicators were analysed separately and are reported elsewhere (Chapman et al., under review)

Figure 1 Flow chart of systematic review procedure for identifying citations reporting indicators of alcohol use and related harms by gender.

system (Diagnostic and Statistical Manual of Mental Disorders (DSM)-III, DSM-IIIR, DSM-IV), timeframe (lifetime, past 12 months) and type of negative consequence considered (eg, drunkenness, drink driving, risky sexual behaviour). While some of these differences are methodological, others reflect important conceptual distinctions. $^{81}$ Attention to these methodological and conceptual distinctions resulted in an initial coding of 11 key indicators of alcohol use and related harm that were further grouped into three broad categories:

A. Indicators of any alcohol use, including:

1. Prevalence of any alcohol use (categorical),

2. Prevalence of alcohol abstinence (categorical),

3. Total amount of alcohol consumed (continuous),

4. Frequency of alcohol use (ordinal or continuous);

B. Indicators of alcohol use that is suggestive of problematic use, including:

5. Prevalence of heavy episodic or binge drinking (categorical),

6. Prevalence of risky drinking (categorical),

7. Frequency of heavy episodic or binge drinking (ordinal or continuous),

8. Age of onset of alcohol use (continuous);

C. Indicators of alcohol-related harms:
9. Prevalence of alcohol-related problems (categorical), 10. Prevalence of alcohol use disorder (categorical),

11. Frequency of alcohol-related problems (continuous). See (online supplementary file) for more details of individual indicator definitions for each included study.

\section{Study quality}

Study quality was rated based on the critical appraisal tool for use in systematic reviews addressing questions of prevalence developed by Munn et $a l^{82}$ as well as the study design and analysis used to examine gender convergence in indicators of alcohol use and related harms. Level 1 studies were repeated cross-sectional studies that conducted APC analysis; level 2 studies were repeated cross-sectional studies that separated age and cohort effects (either by presenting data across cohorts in a single age group or by presenting data across cohorts in separate age groups); level 3 studies were repeated crosssectional studies that did not attempt to separate age and cohort effects; level 4 studies were single crosssectional studies that reported lifetime estimates of at least one target indicator by sex and age groups (proxy for birth cohorts). Study quality was assessed for all 
Table 4 Summary characteristics of included studies

\begin{tabular}{|c|c|c|}
\hline \multirow[b]{2}{*}{ Characteristic } & \multicolumn{2}{|c|}{$\begin{array}{l}\text { Total } \\
(n=68)\end{array}$} \\
\hline & $\mathbf{n}$ & $\begin{array}{l}\text { Per } \\
\text { cent }\end{array}$ \\
\hline \multicolumn{3}{|l|}{ Design } \\
\hline Repeated cross-sectional & 48 & 70.6 \\
\hline Single cross-sectional & 19 & 27.9 \\
\hline Longitudinal & 1 & 1.5 \\
\hline \multicolumn{3}{|l|}{ World region* } \\
\hline North America & 25 & 36.7 \\
\hline Europe & 27 & 39.7 \\
\hline Asia & 4 & 5.9 \\
\hline Oceania & 5 & 7.4 \\
\hline Other world region & 2 & 2.9 \\
\hline$>1$ world region & 5 & 7.4 \\
\hline \multicolumn{3}{|l|}{ Sample age ${ }^{\star}$} \\
\hline Adolescent and young adult (11-26) & 18 & 26.5 \\
\hline Adult $(18+)$ & 28 & 41.2 \\
\hline Adolescent and adult (12+) & 21 & 30.9 \\
\hline \multicolumn{3}{|l|}{ Sample size ${ }^{\star}$} \\
\hline 1000-4999 & 16 & 23.5 \\
\hline 5000-9999 & 11 & 16.2 \\
\hline $10000-19999$ & 10 & 14.7 \\
\hline $20000-49999$ & 9 & 13.2 \\
\hline $50000-99999$ & 10 & 14.7 \\
\hline$>100000$ & 9 & 13.5 \\
\hline \multicolumn{3}{|c|}{ Indicator type (broad category and individual indicator) $\dagger$} \\
\hline Indicators of any alcohol use & 35 & 51.5 \\
\hline Prevalence of any use & 26 & 38.2 \\
\hline Prevalence of abstinence & 11 & 16.2 \\
\hline Total amount of alcohol consumed & 19 & 27.9 \\
\hline Frequency of alcohol use & 5 & 7.4 \\
\hline Indicators of problematic alcohol use & 30 & 44.1 \\
\hline $\begin{array}{l}\text { Prevalence of heavy episodic or binge } \\
\text { drinking }\end{array}$ & 10 & 14.7 \\
\hline Prevalence of risky drinking & 16 & 14.9 \\
\hline $\begin{array}{l}\text { Frequency of heavy episodic or binge } \\
\text { drinking }\end{array}$ & 5 & 7.4 \\
\hline Age of onset of alcohol use & 8 & 11.8 \\
\hline Indicators of alcohol-related harms & 18 & 26.5 \\
\hline $\begin{array}{l}\text { Prevalence of alcohol-related problems or } \\
\text { negative consequences }\end{array}$ & 18 & 26.5 \\
\hline Prevalence of alcohol use disorder & 13 & 19.1 \\
\hline $\begin{array}{l}\text { Frequency of alcohol-related problems or } \\
\text { negative consequences }\end{array}$ & 4 & 5.9 \\
\hline \multicolumn{3}{|c|}{$\begin{array}{l}\text { *Summary groupings are presented here; however, estimates } \\
\text { included in meta-analysis coded country, sample age and size } \\
\text { specific to each estimate. Sample size and age were not reported } \\
\text { by all studies. } \\
\text { †Percentages sum to }>100 \% \text { for alcohol indicators as many } \\
\text { studies reported data on more than one indicator. }\end{array}$} \\
\hline
\end{tabular}

included studies by two independent raters, with final ratings achieved through consensus.

\section{Statistical analysis}

In addition to the extracted qualitative data described above, quantitative data (eg, percentages, means, etc) on the 11 key indicators for each available birth cohort for males and females were also extracted and summarised using meta-analysis. To facilitate quantitative synthesis across varying indicator definitions, we calculated a single metric, the male-to-female ratio, to express the relationship between male and female levels of alcohol use and related harms. This sex ratio represents the relative, not absolute, difference between males and females. A value $>1$ indicates greater alcohol use or more alcohol-related harms in males compared with females. For two indicators, age of onset of alcohol use and alcohol abstinence, the ratio was reversed. Sex ratios on each of the 11 key indicators were calculated separately for each birth cohort in each study where data were available. For sex ratios based on binary indicators, estimates in which both the male and female prevalence fell below 5\% ( $\mathrm{n}=39,2.4 \%$ of all estimates) were considered base rate outliers and not further analysed. Sensitivity analyses indicated that this exclusion did not impact the overall findings. All sex ratios were logarithmically transformed and all meta-analyses were carried out on these logarithmically transformed values, with back-transformation for reporting purposes. Log sex ratios for binary indicators were considered equivalent to $\log$ risk ratios and SEs were calculated accordingly. SEs for each $(\log )$ sex ratio derived from means of continuous indicators were calculated using formulae contained in Friedrich et al. ${ }^{83}$ Pooled ( $\log$ ) sex ratios with 95\% CIs were calculated separately for each birth cohort with STATA (V.12.1). Significant heterogeneity, as assessed by the $\mathrm{I}^{2}$ index, was evident. Thus, random-effects meta-analyses were carried out and statistical heterogeneity was handled using the Knapp-Hartung approach Cornell et al. ${ }^{84}$ Random-effects metaregression analyses were carried out to determine how much of this heterogeneity in sex ratios was explained by birth cohort, controlling for important methodological characteristics. These characteristics included age at the time of data collection, world region, study design and indicator timeframe. These analyses were carried out and are presented separately for each of the three broad alcohol indicator categories. Formal tests of publication bias were not applicable in the context of the current analysis.

\section{RESULTS}

\section{Summary of characteristics of included studies}

We identified 68 citations that met inclusion criteria (see figure 1, (online supplementary file) and table 4). Data used in the studies were collected between the years 1948 and 2014 representing birth cohorts from 1891 to 2000. One-quarter of the studies used data collected across a timespan of 20 years or more $(n=16), 5$ of which used data collected over 30 years or more. More than one-third of studies $(36.7 \%)$ were conducted in North America, $39.7 \%$ in Europe, $5.9 \%$ in Asia, $7.4 \%$ in Oceania, $2.9 \%$ in another world region and $7.4 \%$ across more than one world region. Study sample sizes ranged from 1056 to 809281 (median 15 144); 27.9\% of studies had a sample 
size of $>50000$, resulting in a combined total sample size of 4426673 . The majority of studies were repeated crosssectional studies $(n=48), 8$ of which conducted APC analyses, 19 were single cross-sectional studies and 1 used data from a longitudinal study. The most common assessment timeframe used was lifetime $(n=27)$ followed by past 12 months $(n=17)$. The most common indicator group examined was indicators of any alcohol use $(\mathrm{N}=35)$, followed by indicators of problematic alcohol use $(\mathrm{N}=30)$ and indicators of alcohol-related harms $(n=18)$. Following qualitative review, 42 of the 68 studies reported evidence of sex convergence in recent cohorts on at least one alcohol indicator (see online supplementary file). The majority of these $(n=31 ; 73.8 \%)$ reported that convergence was driven by greater and/or more consistent increases in subsequent birth cohorts on one or more alcohol indicators among females compared with males. Six studies reported that convergence was driven by decreases in males across birth cohorts and five studies reported mixed findings depending on the country or indicator under investigation.

\section{Individual study estimates}

Of the 68 citations, we identified 50 that provided indicator estimates separately for males and females across at least two separate birth cohorts. While not every citation provided estimates in every birth cohort, collectively these citations spanned birth cohorts starting in 1891 and ending in 2000. These citations allowed for the calculation of 1568 separate sex ratios, 845 related to any alcohol use, 439 to problematic alcohol use and 323 to alcohol-related harm. Owing to low numbers of estimates, the earliest four birth cohorts were collapsed into one category (18911910), as were the latest two birth cohorts (1991-2000). Among the subset of $\mathrm{n}=518$ estimates based on categorical indicators of any alcohol use, the matched female (x-axis) and male (y-axis) prevalence estimates are graphed, by birth cohort, in figure 2. A diagonal line is superimposed on each graph indicating where male and female estimates would be equal and therefore where the sex ratio would be 1 . As expected, most estimates fall above this line of equality, denoting a male excess in the prevalence of any alcohol use. However, in recent birth cohorts, particularly those born from 1976 onwards, the estimates are shifting closer to the line of equality, indicating a narrowing of the male-female gap.

\section{Pooled results from meta-analyses}

For all three broad indicator categories (any alcohol use, problematic alcohol use and alcohol-related harms), the pooled sex ratios declined over successive birth cohorts (see tables 5-7). With regard to indicators of any alcohol

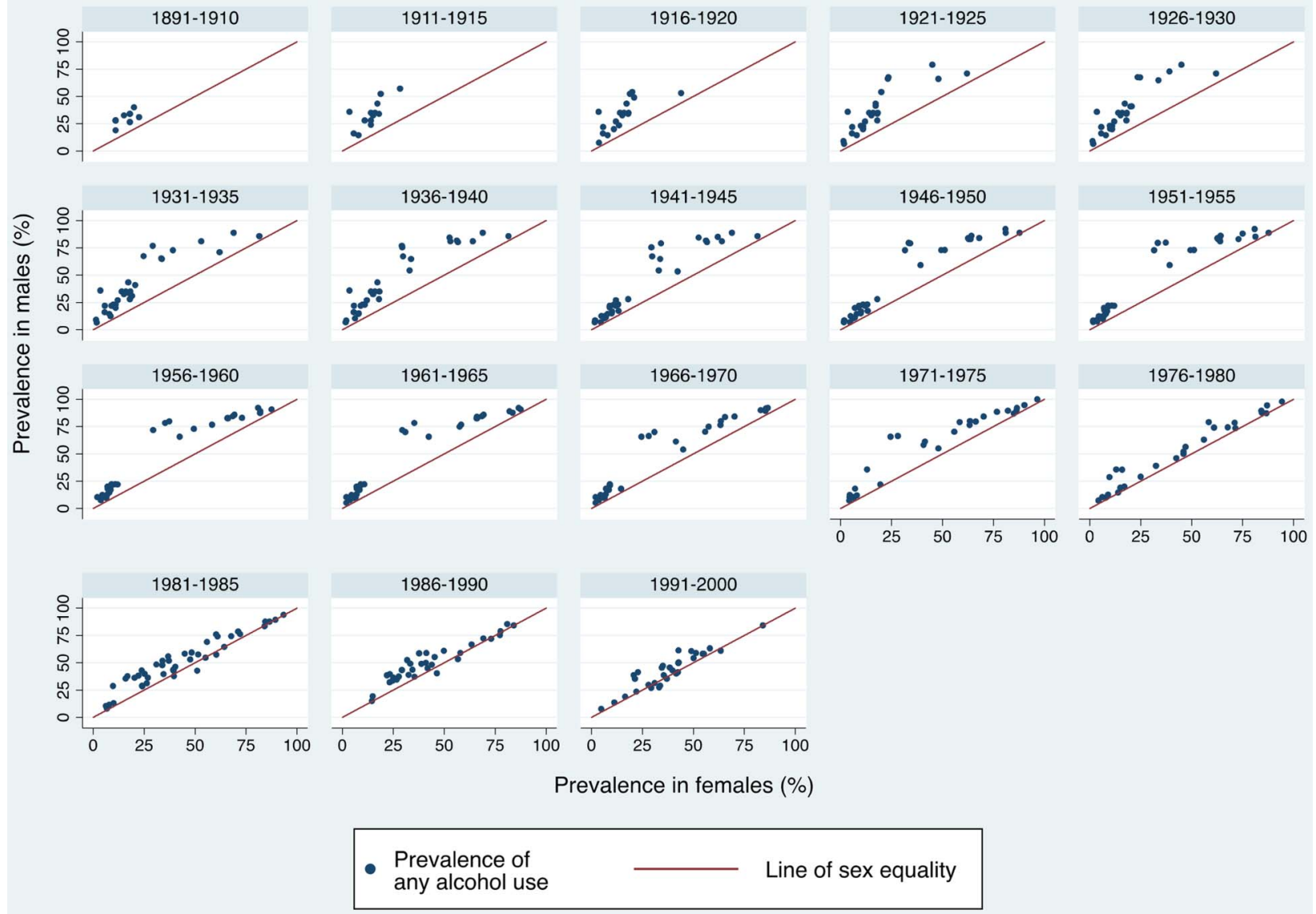

Figure 2 Prevalence of any alcohol use (\%) in females (x-axis) and males (y-axis) by 5-year birth cohort. Each dot represents a single prevalence estimate. 
Table 5 Random-effects meta-analysis pooled sex ratios for indicators of any alcohol use within 5-year birth cohorts

\begin{tabular}{llccc}
\hline Birth cohort & $\begin{array}{l}\text { Number of individual } \\
\text { sex ratio estimates }\end{array}$ & $\begin{array}{l}\text { Number of } \\
\text { citations }\end{array}$ & $\begin{array}{l}\text { Number of } \\
\text { countries }\end{array}$ & $\begin{array}{l}\text { Random-effects pooled } \\
\text { sex ratio (95\% Cl) }\end{array}$ \\
\hline $1891-1910$ & 23 & 7 & 6 & $2.2(1.9$ to 2.5$)$ \\
$1911-1915$ & 25 & 9 & 9 & $2.4(2.1$ to 2.8$)$ \\
$1916-1920$ & 34 & 9 & 9 & $2.4(2.1$ to 2.7$)$ \\
$1921-1925$ & 42 & 13 & 12 & $2.3(2.1$ to 2.6$)$ \\
$1926-1930$ & 47 & 14 & 12 & $2.4(2.2$ to 2.7$)$ \\
$1931-1935$ & 54 & 19 & 14 & $2.3(2.1$ to 2.6$)$ \\
$1936-1940$ & 56 & 19 & 15 & $2.3(2.1$ to 2.6$)$ \\
$1941-1945$ & 58 & 20 & 16 & $2.1(1.9$ to 2.3$)$ \\
$1946-1950$ & 60 & 19 & 18 & $2.0(1.8$ to 2.3$)$ \\
$1951-1955$ & 57 & 20 & 18 & $2.0(1.8$ to 2.3$)$ \\
$1956-1960$ & 56 & 21 & 17 & $2.0(1.8$ to 2.3$)$ \\
$1961-1965$ & 52 & 20 & 18 & $2.0(1.8$ to 2.3$)$ \\
$1966-1970$ & 48 & 18 & 20 & $2.0(1.8$ to 2.2$)$ \\
$1971-1975$ & 45 & 20 & 21 & $1.7(1.5$ to 1.9$)$ \\
$1976-1980$ & 45 & 20 & 35 & $1.5(1.4$ to 1.7$)$ \\
$1981-1985$ & 58 & 19 & 30 & $1.3(1.2$ to 1.4$)$ \\
$1986-1990$ & 40 & 11 & 27 & $1.2(1.2$ to 1.3$)$ \\
$1991-2000$ & 33 & 6 & $1.1(1.1$ to 1.2$)$
\end{tabular}

${ }^{*}$ Represents the number of citations from which the individual estimates were extracted. Some citations reported results from separate repeated cross-sectional surveys, or separate surveys conducted in a number of different countries.

Table 6 Random-effects meta-analysis pooled sex ratios for indicators of problematic alcohol use within 5-year birth cohorts

\begin{tabular}{llccl}
\hline Birth cohort & $\begin{array}{l}\text { Number of individual } \\
\text { sex ratio estimates }\end{array}$ & $\begin{array}{l}\text { Number of } \\
\text { citations* }\end{array}$ & $\begin{array}{l}\text { Number of } \\
\text { countries }\end{array}$ & $\begin{array}{l}\text { Random-effects pooled } \\
\text { sex ratio (95\% Cl) }\end{array}$ \\
\hline $1891-1910$ & 12 & 6 & 6 & $3.0(1.5$ to 6.0$)$ \\
$1911-1915$ & 12 & 6 & 9 & $2.7(1.3$ to 5.8$)$ \\
$1916-1920$ & 18 & 8 & 9 & $2.8(1.6$ to 5.1$)$ \\
$1921-1925$ & 19 & 7 & 12 & $2.2(1.4$ to 3.3$)$ \\
$1926-1930$ & 21 & 9 & 12 & $2.2(1.5$ to 3.3$)$ \\
$1931-1935$ & 22 & 9 & 14 & $2.3(1.6$ to 3.3$)$ \\
$1936-1940$ & 31 & 15 & 15 & $2.3(1.8$ to 2.9$)$ \\
$1941-1945$ & 31 & 14 & 16 & $2.3(1.7$ to 3.0$)$ \\
$1946-1950$ & 35 & 16 & 18 & $2.0(1.6$ to 2.5$)$ \\
$1951-1955$ & 33 & 15 & 18 & $2.2(1.8$ to 2.8$)$ \\
$1956-1960$ & 34 & 13 & 17 & $2.0(1.7$ to 2.4$)$ \\
$1961-1965$ & 27 & 15 & 18 & $2.1(1.6$ to 2.8$)$ \\
$1966-1970$ & 28 & 15 & 20 & $2.0(1.5$ to 2.5$)$ \\
$1971-1975$ & 27 & 15 & 21 & $2.0(1.5$ to 2.7$)$ \\
$1976-1980$ & 28 & 14 & 35 & $1.9(1.5$ to 2.3$)$ \\
$1981-1985$ & 27 & 6 & 30 & $1.6(1.3$ to 2.0$)$ \\
$1986-1990$ & 13 & 3 & 27 & $1.2(0.9$ to 1.5$)$ \\
$1991-2000$ & 4 & 15 & $1.2(1.1$ to 1.4$)$
\end{tabular}

${ }^{*}$ Represents the number of citations from which the individual estimates were extracted. Some citations reported results from separate repeated cross-sectional surveys, or separate surveys conducted in a number of different countries.

use, the sex ratio was 2.2 (95\% CI 1.9 to 2.5$)$ in the $1891-$ 1910 birth cohort indicating that males born between 1891 and 1910 were around two times more likely to report any alcohol use than their female counterparts born during the same time. The sex ratios decreased to a low of 1.1 (95\% CI 1.1 to 1.2) in those born between 1991 and 2000. The same pattern of findings was evident for indicators of problematic alcohol use (declining from 3.0 (95\% CI 1.5 to 6.0 ) in the 1891-1910 birth cohort to 1.2 (95\% CI 0.9 to
1.5) in the 1991-2000 birth cohort) and indicators of alcohol-related harm (declining from 3.6 (95\% CI 0.4 to 30.4) in the 1891-1910 birth cohort to 1.3 (95\% CI 1.2 to 1.3) in the 1991-2000 birth cohort). For all three broad indicator categories, metaregression analyses indicated that the sex ratio declined linearly across birth cohorts. For example, for indicators of any alcohol use when birth cohort was entered into the metaregression as a continuous variable, each successive 5-year birth cohort was 
Table 7 Random-effects meta-analysis pooled sex ratios for indicators of alcohol-related harms within 5-year birth cohorts

\begin{tabular}{llcll}
\hline Birth cohort & $\begin{array}{l}\text { Number of individual } \\
\text { sex ratio estimates }\end{array}$ & $\begin{array}{l}\text { Number of } \\
\text { citations* }\end{array}$ & $\begin{array}{l}\text { Number of } \\
\text { countries }\end{array}$ & $\begin{array}{l}\text { Random-effects pooled } \\
\text { sex ratio (95\% Cl) }\end{array}$ \\
\hline $1891-1910$ & 0 & - & - & - \\
$1911-1915$ & 3 & 2 & 9 & $3.6(0.4$ to 30.4$)$ \\
$1916-1920$ & 3 & 4 & 9 & $3.6(0.4$ to 30.4$)$ \\
$1921-1925$ & 4 & 4 & 12 & $3.8(0.8$ to 18.1$)$ \\
$1926-1930$ & 6 & 5 & 12 & $4.1(1.4$ to 11.8$)$ \\
$1931-1935$ & 7 & 8 & 14 & $2.4(1.6$ to 3.6$)$ \\
$1936-1940$ & 11 & 8 & 16 & $2.2(1.6$ to 2.9$)$ \\
$1941-1945$ & 12 & 10 & 18 & $2.1(1.6$ to 2.8$)$ \\
$1946-1950$ & 16 & 10 & 18 & $2.6(1.8$ to 3.6$)$ \\
$1951-1955$ & 17 & 10 & 18 & $2.2(1.6$ to 2.9$)$ \\
$1956-1960$ & 17 & 10 & 17 & $2.1(1.6$ to 2.9$)$ \\
$1961-1965$ & 16 & 10 & 18 & $2.2(1.6$ to 2.9$)$ \\
$1966-1970$ & 16 & 10 & 20 & $2.0(1.6$ to 2.7$)$ \\
$1971-1975$ & 22 & 13 & 21 & $2.1(1.7$ to 2.7$)$ \\
$1976-1980$ & 21 & 14 & 35 & $1.8(1.5$ to 2.1$)$ \\
$1981-1985$ & 64 & 13 & 30 & $1.5(1.3$ to 1.6$)$ \\
$1986-1990$ & 27 & 5 & 27 & $1.3(1.2$ to 1.4$)$ \\
$1991-2000$ & 51 & 4 & $1.3(1.2$ to 1.3$)$ \\
\hline
\end{tabular}

${ }^{*}$ Represents the number of citations from which the individual estimates were extracted. Some citations reported results from separate repeated cross-sectional surveys, or separate surveys conducted in a number of different countries.

associated with a $4.2 \%$ (95\% CI $3.7 \%$ to $4.6 \%, \mathrm{t}=-16.14$, $\mathrm{p}<0.001)$ decrease in the sex ratio. This effect remained once controlling for methodological characteristics. With these characteristics included in the model, the sex ratio decreased linearly by $3.2 \%$ (95\% CI $2.4 \%$ to $4.0 \%$, $\mathrm{t}=-7.85$, $\mathrm{p}<0.001$ ) with each successive 5-year birth cohort.

\section{DISCUSSION}

The current study summarised the available published literature on sex convergence in indicators of alcohol use and related harms across the world. By extracting estimates from studies and deriving a single metric, the male-to-female ratio, we were able to use meta-analysis to numerically summarise the overall relationship of male-to-female alcohol use, problematic alcohol use and alcohol-related harms. To the best of our knowledge, this is the first study to do so. The results of the meta-analysis indicate that the male-female gap in alcohol use is closing over time.

The results of the qualitative review demonstrated support for sex convergence among recent cohorts. Sixty-two per cent of identified studies found evidence of sex convergence among recent cohorts on at least 1 of the 11 individual alcohol-related indicators, 4 of which were APC analyses. Meta-analysis confirmed these qualitative results indicating, for example, that the sex ratio in any alcohol use has decreased from 2.2 among those born in the earliest years of the 20th century to 1.1 among those born during the end of the 20th century. Follow-up analyses on the rate of change in sex ratios demonstrated that the decline in the sex ratio was steepest in cohorts born from 1966 onwards. For example, overall, the sex ratios for any alcohol use decreased by $4.2 \%$ with each successive 5-year birth cohort between 1891 and 2000. However, this rate of change was $1.2 \%$ for successive cohorts born from 1891 to 1966 and $10.1 \%$ for cohorts born from 1966 to 2000 .

It is important to note that the sex ratio metric used in the current study provides information on the relative prevalence of alcohol use or related harms in males versus females. This metric does not empirically determine whether observed changes in the sex ratio are being driven by increases or decreases in male or female prevalence or whether, in fact, there is a more complex indicator-specific and/or birth cohort-dependent relationship between male and female alcohol use and/or harms that is driving the change in sex ratios over time. However, the qualitative review determined that of the 42 studies that reported some evidence for sex convergence in alcohol use or related harms, the majority of these reported that convergence was driven by greater and/or more consistent increases in indicators of alcohol use among females compared with males from recent cohorts. ${ }^{5} \begin{array}{lllllllllllll}6 & 8 & 9 & 11 & 14 & 15 & 25 & 27 & 32-34 & 39 & 41 & 42 & 44\end{array}$ 46-48 $515558-6065-6769717578$ Within this context, it is interesting to note that $5 \%$ of the sex ratios were $<1$, indicating that, in some cases, females have surpassed males in their drinking levels. The majority of such estimates $(60 \%)$ came from cohorts born after 1981 .

A number of limitations require discussion. We restricted our search to published studies and did not include an assessment of the grey literature, thus increasing the chances of publication bias. The databases searched were not exhaustive of all possible databases. However, they did represent three of the largest 
and most commonly searched health-related databases. The pooling of estimates within birth cohorts across studies meant we are not able to use traditional publication bias assessments. ${ }^{85}$ However, our conclusions were informed most by large nationally representative surveys several of which were strengthened by APC analyses, and it is unlikely that we would have missed large unpublished surveys or relevant APC studies that were only available in the grey literature. Moreover, our findings are consistent with the latest data on trends and social disparities in alcohol consumption in Organization for Economic Co-operation and Development (OECD) member countries around the world. ${ }^{86}$ While the derivation of a single metric facilitated numerical synthesis of data, the analyses are not independent of measurement variance. If, for example, definitions that are associated with smaller sex ratios were more likely to be used by studies reporting recent cohorts, this could have inflated the observed cohort effect on sex convergence. While the number of different definitions used by studies precludes direct testing of this effect, the fact that sex convergence across birth cohorts was found controlling for important methodological characteristics and across the three broad categories of indicators examined, implies that the finding is at least somewhat robust to the variability in methods and measurement across studies. Finally, $68 \%$ of studies included in the meta-analysis reported data on multiple indicators and as such a significant proportion of the sex ratios were derived from the same respondents within a given study. While violating the assumption of independence, this multiplicity was far more often observed across rather than within the broad indicator categories. Given we pooled sex ratios within broad indicator categories, this observation is unlikely to impact on the summary estimates.

The current study did not test specific hypotheses for why the male-female gap in substance use is closing. However, speculative explanations can be proposed. Changes over time in female gender role traditionality may be one explanation for the closing male-female gap. In a large multicountry epidemiological study, Seedat et $a \tilde{l}$ measured female gender role traditionality using female-to-male ratios in factors such as the percentage participating in the labour force by age 35 , the percentage with education levels in the upper quartile of the income distribution and the median age of first marriage. Using this definition, they demonstrated that the narrowing sex differences in the prevalence of substance use disorders across birth cohorts were strongest in those countries where female and male roles were converging over time. Beyond the impact of changing gender role traditionality, some have suggested that broader social, cultural and economic developments explain converging patterns of substance use in males and females. ${ }^{87}$ The large-scale GENACIS (Gender, Alcohol and Culture: An International Study) project has shown that sex differences in alcohol use are linked, albeit in complex ways, to greater engagement by females in paid employment outside the home. ${ }^{12}$ In a novel examination of generational changes in female drinking over a period of three decades, Alati $e t a l^{88}$ demonstrated that the daughters of 1053 mother/daughter dyads had more than five times the odds of heavy drinking than their mothers had at the same age. Moreover, they demonstrated that this increase was partly accounted for by later age at childbearing thus providing much needed direct evidence on potential mechanisms driving the generational increase in alcohol consumption.

These results have implications for the framing and targeting of alcohol use prevention and intervention programmes. Alcohol use and alcohol use disorders have historically been viewed as a male phenomenon. The present study calls this assumption into question and suggests that young women in particular should be the target of concerted efforts to reduce the impact of substance use and related harms. Those born in the most recent cohorts (ie, the 1990s) can, by definition, only have a maximum age of between 15 and 25. That the birth cohort effect on sex ratios has become more pronounced in these recent birth cohorts points to the value of continuing to focus research on adolescent and young adult sex-specific trends in substance use. Given that this young age group are relatively early in their alcohol use careers, these findings highlight the importance of further tracking young male and female cohorts as they age into their $30 \mathrm{~s}, 40 \mathrm{~s}$ and beyond.

Acknowledgements The research team would like to thank Ms Mary Kumvaj (NDARC Librarian) who provided helpful advice on the development of search strings for the relevant databases.

Contributors TS and CC conceived of the study, developed and implemented the search strategy, independently screened article abstracts for inclusion, developed the data coding scheme, coded the data, analysed the data, and drafted and revised the paper. They are the guarantors. WS coded the data, and contributed to drafting and revising the paper. KK contributed to interpretation of the data and to drafting and revising the paper. ZT independently screened article abstracts for inclusion, coded the data and contributed to drafting and revising the paper, MT conceived of the study and drafted and revised the paper.

Funding This work was supported by the Australian Government under the Substance Misuse Prevention and Service Improvements Grants Fund; and a National Health and Medical Research Council Centre of Research Excellence Grant (NHMRC APP1041129). KK is supported by NIAAA: K01AA021511.

\section{Competing interests None declared}

Provenance and peer review Not commissioned; externally peer reviewed.

Data sharing statement No additional data are available.

Open Access This is an Open Access article distributed in accordance with the Creative Commons Attribution Non Commercial (CC BY-NC 4.0) license, which permits others to distribute, remix, adapt, build upon this work noncommercially, and license their derivative works on different terms, provided the original work is properly cited and the use is non-commercial. See: http:// creativecommons.org/licenses/by-nc/4.0/

\section{REFERENCES}

1. Lim SS, Vos T, Flaxman AD, et al. A comparative risk assessment of burden of disease and injury attributable to 67 risk factors and risk factor clusters in 21 regions, 1990-2010: a systematic analysis for 
the Global Burden of Disease Study 2010. Lancet 2012;380:2224-60.

2. Grant BF, Dawson DA, Stinson FS, et al. The 12-month prevalence and trends in DSM-IV alcohol abuse and dependence: United States, 1991-1992 and 2001-2002. Drug Alcohol Depend 2004;74:223-34.

3. Hahm BJ, Cho MJ. Prevalence of alcohol use disorder in a South Korean community: changes in the pattern of prevalence over the past 15 years. Soc Psychiatry Psychiatr Epidemiol 2005;40:114-19.

4. Holmila M, Raitasalo K. Gender differences in drinking: why do they still exist? Addiction 2005;100:1763-9.

5. Seedat S, Scott KM, Angermeyer MC, et al. Cross-national associations between gender and mental disorders in the World Health Organization World Mental Health Surveys. Arch Gen Psychiatry 2009;66:785-95.

6. Bromet EJ, Gluzman SF, Paniotto VI, et al. Epidemiology of psychiatric and alcohol disorders in Ukraine: findings from the Ukraine World Mental Health Survey. Soc Psychiatry 2005;40:681-90.

7. Khan S, Okuda M, Hasin DS, et al. Gender differences in lifetime alcohol dependence: results from the national epidemiologic survey on alcohol and related conditions. Alcohol Clin Exp Res 2013;37:1696-705

8. Degenhardt L, Chiu WT, Sampson N, et al. Toward a global view of alcohol, tobacco, cannabis, and cocaine use: findings from the WHO World Mental Health Surveys. PLoS Med 2008;5:e141.

9. Keyes KM, Grant BF, Hasin DS. Evidence for a closing gender gap in alcohol use, abuse, and dependence in the United States population. Drug Alcohol Depend 2008;93:21-9.

10. Kallmen $\mathrm{H}$, Wennberg $\mathrm{P}$, Leifman $\mathrm{H}$, et al. Alcohol habits in Sweden during 1997-2009 with particular focus on 2005 and 2009, assessed with the AUDIT: a repeated cross-sectional study. Eur Addict Res 2011;17:90-6.

11. Colell E, Sanchez-Niubo A, Domingo-Salvany A. Sex differences in the cumulative incidence of substance use by birth cohort. Int $J$ Drug Policy 2013;24:319-25.

12. Kuntsche S, Knibbe RA, Kuntsche E, et al. Housewife or working mum-each to her own? The relevance of societal factors in the association between social roles and alcohol use among mothers in 16 industrialized countries. Addiction 2011;106:1925-32.

13. Fitzgerald N, Angus K, Emslie C, et al. Gender differences in the impact of population-level alcohol policy interventions: evidence synthesis of systematic reviews. Addiction 2016. doi:10.1111/add. 13452

14. Harkonen JT, Makela P. Age, period and cohort analysis of light and binge drinking in Finland, 1968-2008. Alcohol Alcohol 2011:46:349-56.

15. Bjork C, Thygesen LC, Vinther-Larsen M, et al. Time trends in heavy drinking among middle-aged and older adults in Denmark. Alcohol Clin Exp Res 2008;32:120-7.

16. Meng Y, Holmes J, Hill-McManus D, et al. Trend analysis and modelling of gender-specific age, period and birth cohort effects on alcohol abstention and consumption level for drinkers in Great Britain using the General Lifestyle Survey 1984-2009. Br J Addict 2014:109:206-15

17. Keyes KM, Miech R. Age, period, and cohort effects in heavy episodic drinking in the US from 1985 to 2009. Drug Alcohol Depend 2013;132:140-8.

18. Kerr WC, Greenfield TK, Ye Y, et al. Are the 1976-1985 birth cohorts heavier drinkers? Age-period-cohort analyses of the National Alcohol Surveys 1979-2010. Addiction 2013:108:1038-48.

19. Keyes KM, Li G, Hasin DS. Birth cohort effects and gender differences in alcohol epidemiology: a review and synthesis. Alcohol Clin Exp Res 2011;35:2101-12.

20. Stroup DF, Berlin JA, Morton SC, et al. Meta-analysis of observational studies in epidemiology: a proposal for reporting Meta-analysis Of Observational Studies in Epidemiology (MOOSE) group. JAMA 2000;283:2008-12.

21. Liberati A, Altman DG, Tetzlaff $J$, et al. The PRISMA statement for reporting systematic reviews and meta-analyses of studies that evaluate health care interventions: explanation and elaboration. PLoS Med 2009;6:e1000100.

22. Shamseer $L$, Moher $D$, Clarke $M$, et al. Preferred reporting items for systematic review and meta-analysis protocols (PRISMA-P) 2015: elaboration and explanation. BMJ 2015;349:g7647.

23. Brugha TS, Matthews R, Morgan Z, et al. Methodology and reporting of systematic reviews and meta-analyses of observational studies in psychiatric epidemiology: systematic review. Br J Psychiatry 2012;200:446-53.

24. Whiteford HA, Ferrari AJ, Baxter AJ, et al. How did we arrive at burden of disease estimates for mental and illicit drug use disorders in the Global Burden of Disease Study 2010? Curr Opin Psychiatry 2013;26:376-83.

25. Barnes GM, Welte JW, Hoffman JH, et al. Changes in alcohol use and alcohol-related problems among 7th to 12th grade students in New York State, 1983-1994. Alcohol Clin Exp Res 1997;21:916-22.

26. Bergmark KH. Gender roles, family, and drinking: women at the crossroad of drinking cultures. J Fam Hist 2004;29:293-307.

27. Bloomfield K, Gmel G, Neve R, et al. Investigating gender convergence in alcohol consumption in Finland, Germany, The Netherlands, and Switzerland: a repeated survey analysis. Subst Abus 2001;22:39-53.

28. Breslow RA, Faden VB, Smothers B. Alcohol consumption by elderly Americans. J Stud Alcohol 2003;64:884-92.

29. Brooks-Russell A, Farhat T, Haynie D, et al. Trends in substance use among 6th- to 10th-grade students from 1998 to 2010: findings from a national probability study. J Early Adolesc 2014;34:667-80.

30. Cabrera $\mathrm{C}$, Wilhelmson $\mathrm{K}$, Allebeck $\mathrm{P}$, et al. Cohort differences in obesity-related health indicators among 70-year olds with special reference to gender and education. Eur J Epidemiol 2003;18:883-90.

31. Grant BF. Prevalence and correlates of alcohol use and DSM-IV alcohol dependence in the United States: results of the National Longitudinal Alcohol Epidemiologic Survey. J Stud Alcohol 1997;58:464-73.

32. Grucza RA, Bucholz KK, Rice JP, et al. Secular trends in the lifetime prevalence of alcohol dependence in the United States: a re-evaluation. Alcohol Clin Exp Res 2008;32:763-70.

33. Grucza RA, Norberg KE, Bucholz KK, et al. Correspondence between secular changes in alcohol dependence and age of drinking onset among women in the United States. Alcohol Clin Exp Res 2008;32:1493-501.

34. Gum AM, King-Kallimanis B, Kohn R. Prevalence of mood, anxiety, and substance-abuse disorders for older Americans in the national comorbidity survey-replication. Am J Geriatr Psychiatry 2009;17:769-81.

35. Hasin DS, Grant BF. The co-occurrence of DSM-IV alcohol abuse in DSM-IV alcohol dependence: results of the National Epidemiologic Survey on Alcohol and Related Conditions on heterogeneity that differ by population subgroup. Arch Gen Psychiatry 2004;61:891-6.

36. Hill DJ, White VM, Williams RM, et al. Tobacco and alcohol use among Australian secondary school students in 1990. Med J Aust 1993;158:228-34.

37. Hilton ME. Trends in drinking problems and attitudes in the United States: 1979-1984. Br J Addict 1988;83:1421-7.

38. Huckle $T$, You Ru Q, Casswell S. Increases in quantities consumed in drinking occasions in New Zealand 1995-2004. Drug Alcohol Rev 2011;30:366-71.

39. Johnson RA, Gerstein DR. Initiation of use of alcohol, cigarettes, marijuana, cocaine, and other substances in US birth cohorts since 1919. Am J Public Health 1998;88:27-33.

40. Johnson RA, Gerstein DR. Age, period, and cohort effects in marijuana and alcohol incidence: United States females and males, 1961-1990. Subst Use Misuse 2000;35:925-48.

41. Karam EG, Maalouf WE, Ghandour LA. Alcohol use among university students in Lebanon: prevalence, trends and covariates. The IDRAC University Substance Use Monitoring Study (1991 and 1999). Drug Alcohol Depend 2004;76:273-86.

42. Kemm J. An analysis by birth cohort of alcohol consumption by adults in Great Britain 1978-1998. Alcohol Alcohol 2003;38:142-7.

43. Kerr WC, Greenfield TK, Bond J, et al. Age, period and cohort influences on beer, wine and spirits consumption trends in the US National Alcohol Surveys. Addiction 2004;99:1111-20.

44. Kerr WC, Greenfield TK, Bond J, et al. Age-period-cohort modelling of alcohol volume and heavy drinking days in the US National Alcohol surveys: divergence in younger and older adult trends. Addiction 2009;104:27-37.

45. Keyes KM, Martins SS, Blanco C, et al. Telescoping and gender differences in alcohol dependence: new evidence from two national surveys. Am J Psychiatry 2010;167:969-76.

46. Kim JH, Lee S, Chow J, et al. Prevalence and the factors associated with binge drinking, alcohol abuse, and alcohol dependence: a population-based study of Chinese adults in Hong Kong. Alcohol Alcohol 2008;43:360-70.

47. Kokkevi A, Loukadakis M, Plagianakou S, et al. Sharp increase in illicit drug use in Greece: trends from a general population survey on licit and illicit drug use. Eur Addict Res 2000;6:42-9.

48. Kraus L, Bloomfield K, Augustin R, et al. Prevalence of alcohol use and the association between onset of use and alcohol-related problems in a general population sample in Germany. Addiction 2000;95:1389-401. 
49. Kuntsche E, Gmel G. Changes in adolescents' reasons for drinking in Switzerland and associations with alcohol use from 1994 to 2002 $J$ Adolesc Health 2006;39:705-11

50. Kuntsche E, Kuntsche S, Knibbe R, et al. Cultural and gender convergence in adolescent drunkenness: evidence from 23 European and North American countries. Arch Pediatr Adolesc Med 2011;165:152-8.

51. Lim WY, Fong CW, Chan JML, et al. Trends in alcohol consumption in Singapore 1992-2004. Alcohol Alcohol 2007;42:354-61.

52. Marques-Vidal P, Dias Carlos M. Trends and determinants of alcohol consumption in Portugal: results from the National Health Surveys 1995 to 1996 and 1998 to 1999. Alcohol Clin Exp Res 2005;29:89-97.

53. McPherson M, Casswell S, Pledger M. Gender convergence in alcohol consumption and related problems: issues and outcomes from comparisons of New Zealand survey data. Addiction 2004;99:738-48.

54. Melchior M, Chastang J, Goldberg P, et al. High prevalence rates of tobacco, alcohol and drug use in adolescents and young adults in France: results from the GAZEL Youth study. Addict Behav 2008;33:122-33.

55. Mercer PW, Khavari KA. Are women drinking more like men? An empirical examination of the convergence hypothesis. Alcohol Clin Exp Res 1990;14:461-6.

56. Michaud PA, Berchtold A, Jeannin A, et al. Secular trends in legal and illegal substance use among 16-20-year-old adolescents in Switzerland. Swiss Med Wkly 2006;136:318-26.

57. Naimi T, Brewer R, Mokdad A, et al. Binge drinking among US adults. JAMA 2003;289:70-5.

58. Nelson CB, Wittchen HU. DSM-IV alcohol disorders in a genera population sample of adolescents and young adults. Addiction 1998a;93:1065-77.

59. Nelson CB, Heath AC, Kessler RC. Temporal progression of alcoho dependence symptoms in the U.S. household population: results from the National Comorbidity Survey. J Consult Clin Psychol 1998;66:474-83.

60. Neve R, Diederiks J, Knibbe R, et al. Developments in drinking behavior in the Netherlands from 1958 to 1989 , a cohort analysis. Addiction 1993;88:611-21.

61. Neve RJ, Drop MJ, Lemmens PH, et al. Gender differences in drinking behaviour in the Netherlands: convergence or stability? Addiction 1996:91:357-73.

62. Osaki $\mathrm{Y}$, Tanihata $\mathrm{T}$, Ohida $\mathrm{T}$, et al. Decrease in the prevalence of adolescent alcohol use and its possible causes in Japan: periodical nationwide cross-sectional surveys. Alcohol Clin Exp Res 2009;33:247-54.

63. Parry C, Pluddemann A, Steyn K, et al. Alcohol use in South Africa findings from the first Demographic and Health Survey (1998). J Stud Alcohol 2005;66:91-7.

64. Perkins HW. Gender patterns in consequences of collegiate alcoho abuse: a 10-year study of trends in an undergraduate population. $J$ Stud Alcohol 1992;53:458-62.

65. Raum E, Rothenbacher D, Low M, et al. Changes of cardiovascular risk factors and their implications in subsequent birth cohorts of older adults in Germany: a life course approach. Eur J Cardiovasc Prev Rehabil 2007;14:809-14.

66. Roche AM, Deehan A. Women's alcohol consumption: emerging patterns, problems and public health implications. Drug Alcohol Rev 2002;21:169-78.

67. Royo-Bordonada MA, Cid-Ruzafa J, Martin-Moreno JM, et al. Drug and alcohol use in Spain: consumption habits, attitudes and opinions. Public Health 1997;111:277-84.

68. Simons-Morton BG, Farhat T, ter Bogt TF, et al. Gender specific trends in alcohol use: cross-cultural comparisons from 1998 to 2006 in 24 countries and regions. Int J Public Health 2009;54(Suppl 2):199-208

69. Smyth BP, Kelly A, Cox G. Decline in age of drinking onset in Ireland, gender and per capital alcohol consumption. Alcohol Alcohol 2011;46:478-84.

70. Sourander A, Merja K, Solja N, et al. Changes in adolescents mental health and use of alcohol and tobacco: a 10-year time-trend study of Finnish adolescents. Eur Child Adolesc Psychiatry 2012;21:665-71.

71. Stoltenberg S, Hill E, Mudd S, et al. Birth cohort differences in features of antisocial alcoholism among men and women. Alcohol Clin Exp Res 1999;23:1884-91.

72. Vieno A, Lenzi M, Santinello $M$, et al. Gender convergence in adolescent drunkenness in different Italian regions. Int J Public Health 2013;58:785-90.

73. Villalbi JR. Smoking and alcohol use in adolescence in Barcelona, Spain. Health Promot Int 1995;10:267-72.

74. Von Soest T, Wichstrom L. Secular trends in eating problems among Norwegian adolescents from 1992 to 2010. Int J Eat Disord 2014;47:448-57.

75. Waern M, Marlow T, Morin J, et al. Secular changes in at-risk drinking in Sweden: birth cohort comparisons in 75-year-old men and women 1976-2006. Age Ageing 2014;43:228-34.

76. White VM, Hill DJ, Letcher TR. Alcohol use among Australian secondary students in 1996. Drug Alcohol Rev 2000;19:371-9.

77. Wilsnack RW, Wilsnack SC, Kristjanson AF, et al. Gender and alcohol consumption: patterns from the multinational GENACIS project. Addiction 2009;104:1487-500.

78. York JL, Welte J, Hirsch J, et al. Association of age at first drink with current alcohol drinking variables in a national general population sample. Alcohol Clin Exp Res 2004;28:1379-87.

79. Zhang Y, Guo X, Saitz R, et al. Secular trends in alcohol consumption over 50 years: the Framingham Study. Am J Med 2008;121:695-701.

80. Zhong H, Schwartz J. Exploring gender-specific trends in underage drinking across adolescent age groups and measures of drinking: is girls' drinking catching up with boys'? J Youth Adolesc 2010;9:911-26.

81. Dawson DA. Defining risk drinking. Alcohol Res Health 2011;34:144-56.

82. Munn Z, Moola S, Riitano D, et al. The development of a critical appraisal tool for use in systematic reviews addressing questions of prevalence. Int J Health Policy Manag 2014;3:123-8.

83. Friedrich JO, Adhikari NK, Beyene J. The ratio of means method as an alternative to mean differences for analyzing continuous outcome variables in meta-analysis: a simulation study. BMC Med Res Methodol 2008;8:32

84. Cornell JE, Mulrow CD, Localio R, et al. Random-effects metaanalysis of inconsistent effects: a time for change. Ann Intern Med 2014;160:267-70.

85. Begg CB, Mazumdar M. Operating characteristics of a rank correlation test for publication bias. Biometrics 1994;50:1088-101.

86. Sassi F. Tackling harmful alcohol use: economics and public health policy. Paris: OECD Publishing, 2015. doi:10.1787/ 9789264181069-en

87. Wilsnack SC. The GENACIS project: a review of findings and some implications for global needs in women-focused substance abuse prevention and intervention. Subst Abuse Rehabil 2012;3(Suppl 1):5-15.

88. Alati R, Betts KS, Williams GM, et al. Generational increase in young women's drinking: a prospective analysis of mother-daughter dyads. JAMA Psychiatry 2014;71:952-7. 